\title{
Factors limiting oxygen delignification of kraft pulp
}

\author{
Leonid G. Akim, Jorge Luiz Colodette, and Dimitris S. Argyropoulos
}

\begin{abstract}
Softwood kraft pulp was subjected to a laboratory one- and three-stage oxygen delignification process. Pulp and liquor samples were collected at different stages of the process with particular attention being paid to the early and late stages. A novel residual lignin isolation method extracted about $65 \%$ of the oxidized residual lignins at a purity exceeding $90 \%$. Using this methodology coupled to quantitative ${ }^{31} \mathrm{P}$ NMR, ${ }^{13} \mathrm{C}$ NMR, 2D heteronuclear (HMQC) NMR spectroscopic and analytical pyrolysis techniques allowed a thorough characterization of the residual and solubilized lignin fractions at the various stages of the process. Our conclusions do not point to a single factor as being responsible for the limits confronting oxygen delignification. Amongst the major factors impeding the effectiveness of oxygen delignification are: $(i)$ the accumulation of relatively inert 5,5' biphenyl structures originally present in kraft lignin from dibenzodioxocin ring opening reactions; and (ii) the accumulation of considerably less reactive $p$-hydroxyphenyl structures. Detailed quantitative information was obtained and discussed in relation to the presence and role of these unreactive phenolic fractions on the residual oxidized lignins. As such we arrived at important conclusions as to why and how these structures remain and accumulate on the fiber. In addition, issues related to the profiles of the total phenolic hydroxyl content of the residual lignins and the remaining arylglycerol $\beta-O-4$ structures are discussed.
\end{abstract}

Key words: analytical pyrolysis, biphenyl structures, HMQC, NMR, oxidation mechanism, oxygen delignification, $p$-hydroxyphenyl moieties, quantitative ${ }^{13} \mathrm{C}$ NMR, quantitative ${ }^{31} \mathrm{P} N \mathrm{NM}$, residual lignin, solubilized lignin, total phenolic hydroxyls.

Résumé : De la pâte au sulfate (pâte kraft) provenant de bois résineux a été soumise en laboratoire à un processus de délignification par l'oxygène, à une ou trois étapes. Les échantillons de pâte et de liqueurs ont été recueillies à différents stades du processus, en portant une attention particulière aux stades du début et de la fin. Une nouvelle méthode d'isoler la lignine résiduelle a permis d'extraire environ $65 \%$ des lignines résiduelles oxydées, avec un degré de pureté supérieur à $90 \%$. Faisant appel à cette technologie couplée à des techniques spectroscopiques $\left[\mathrm{RMN}\right.$ du ${ }^{31} \mathrm{P}, \mathrm{RMN}$ du ${ }^{13} \mathrm{C}, \mathrm{RMN}$ hétéronucléaire en deux dimensions ( $\left.\left.\mathrm{HMQC} »\right)\right]$ ou d'analyses pyrolytiques, il a été possible de faire une caractérisation complète des fractions de lignines résiduelles et solubilisées, à divers stades du processus. Nos résultats ne permettent pas d'attribuer à un seul facteur les limites auxquelles on doit faire face lors de la délignification par l'oxygène. Parmi les facteurs qui limitent l'efficacité de la délignification par l'oxygène, les plus importants sont: (i) l'accumulation de structures 5,5' biphényles relativement inertes qui sont originalement présentes dans la lignine de la pâte kraft et qui proviennent de réactions d'ouverture de cycles des dibenzodioxocines et; (ii) l'accumulation de structures $p$-hydroxyphényles qui sont beaucoup moins réactives. On a obtenu des informations quantitatives détaillées et on en discute en termes de la présence et du rôle de ces fractions phénoliques non réactives sur les lignines oxydées résiduelles. Sur cette base, on est arrivé à d'importantes conclusions sur le pourquoi et comment ces structures se maintiennent et s'accumulent sur la fibre. De plus, on discute des questions apparentées aux profils en contenu en hydroxyles phénoliques totaux des lignines résiduelles et en structures $\beta$ - $O$-4-arylglycérol résiduelles.

Mots clés : pyrolyse analytique, structures biphényles, HMQC, RMN, mécanisme d'oxydationm délignification par l'oxygène, portions $p$-hydroxyphényles, $\mathrm{RMN} d u{ }^{13} \mathrm{C}$ quantitative, $\mathrm{RMN}$ du ${ }^{31} \mathrm{P}$ quantitative, lignine résiduelle, lignine solubilisée, hydroxyles phénoliques totaux.

[Traduit par la Rédaction]

Received September 21, 2000. Published on the NRC Research Press Web site on March 12, 2001.

L.G. Akim, J.L. Colodette, and D.S. Argyropoulos. ${ }^{1}$ Department of Chemistry, Pulp and Paper Research Centre, McGill University, 3420 University St., Montreal, QC H3A 2A7, Canada.

${ }^{1}$ Corresponding author (e-mail: dargyr@po-box.mcgill.ca).

\section{Introduction}

Regulatory and economic pressures have driven the pulp and paper industry to implement new delignification and bleaching practices. A major transition is the partial replacement of chlorine or chlorine dioxide delignification stages with oxygen delignification. The environmental, technical and economic benefits of oxygen delignification include lower chemical requirements in subsequent bleaching sequences, higher brightness with equivalent amount of chemicals, lower rejects and lower water consumption and subsequent effluent discharge due to the greater recycling potential of 
oxygen stage effluents $(1,2)$. The effectiveness of an oxygen delignification stage is however limited to $50 \%$ delignification. Beyond this level, severe cellulose degradation takes place, resulting in the deterioration of pulp viscosity and strength characteristics $(3,4)$. This selectivity issue is a drawback of oxygen delignification.

A number of approaches aimed at extending oxygen delignification have been proposed and implemented in the industry. Double stage oxygen delignification has shown some potential $(5,6)$. However, even under idealized laboratory conditions, the effectiveness of double stage oxygen delignification with thorough interstage washing failed to exceed $70 \%$ delignification (7). Chirat and Lachenal (8) in their study of multistage oxygen delignification showed that a significant fraction of the residual lignin remains within the pulp even after four stages of oxygen delignification.

Finding ways to obtain lower kappa numbers, using oxygen delignification would curtail the expensive chemicals needed in subsequent bleaching stages. However, achieving a viable "extended" oxygen delignification process is more likely if the mechanisms responsible for limiting the process are better understood. During the past decade a number of studies have addressed lignin oxidation with molecular oxygen under alkaline conditions. The early efforts centered on elucidating the reaction mechanism of oxygen delignification using lignin model compound under homogeneous reaction conditions $(9,10)$. Moieties bearing free phenolic hydroxyls groups exhibited a higher reactivity toward oxidation than their etherified counterparts (11-13). Based on the accumulated data Gierer (14) proposed a reaction mechanism which involves the phenolate anions, formed under the alkaline conditions of the process, being converted into phenoxy radicals followed by the formation of hydroperoxides and the eventual degradation of aromatic rings to muconic acids.

Further developments in this area have been associated with structural studies of residual lignin isolated from oxygen delignified pulp using either acidolysis $(15,16)$ or enzymatic digestion (17). In the early papers of this series, Gellerstedt et al. (15) reported that the residual lignin, in an oxygen-delignified pulp "has few remaining phenolic hydroxyl groups." However, ensuing efforts by Sun and Argyropoulos (18) and Johansson et al. (19) did not confirm such a drastic depletion.

Aromatic condensation reactions have also been thought to decrease the reactivity of lignin moieties toward oxygen delignification $(20,21)$. The reactivity of various condensed units present in kraft pulp were explored using degradation techniques. Condensed structures such as diphenylmethane and biphenyls were found to be resistant during oxygen delignification and were held responsible for the slow phase of oxygen delignification (20). The phenylcoumaran structures were pronounced to be the least stable amongst the resistant condensed moieties (20). The reactivity of the condensed structures within residual kraft lignin under oxygen delignification conditions was recently evaluated in detail (21). Even under homogeneous oxidative conditions with no mass transfer limitations operated, the 5,5' biphenyl condensed structures were found to be fairly stable toward the oxidation.
Despite the many research efforts the question of which structures are responsible for activation and which are responsible for lignin deactivation during oxygen delignification still remains unanswered. Our continuing efforts to address this question are now focused at systematically examining the residual lignins within an oxygen delignified fiber. To do this a newly developed residual lignin isolation method which provided residual lignin in high yield was coupled with a systematic sampling of delignified pulp and spent liquor at different stages of oxygen delignification. The isolated residual and solubilized lignins were then subjected to detailed spectroscopic analyses. This approach allowed a systematic assessment of the structural changes occurring within the lignin during the oxidation process. To strengthen our conclusions and augment our data, lignins isolated from a multistage treatment were also examined.

\section{Experimental}

\section{Oxygen delignification}

Black spruce softwood (Picea mariana) kraft pulp of kappa no. 29.9 was chelated with DTPA for $30 \mathrm{~min}$ at $50^{\circ} \mathrm{C}$ and thoroughly washed before the oxygen delignification process.

A custom-made $2.5 \mathrm{~L}$ kettle reactor was used for oxygen delignification. The reactor was equipped with a central shaft and impellers for effective pulp mixing at medium consistencies. An elaborate computer interface provides a precise control of all major process parameters and of any desired process scenarios.

In all experiments the amount of pulp used in the oxygen delignification stage (oven-dry basis) at a consistency of $10 \%$, an oxygen pressure of $0.68 \mathrm{MPa}$, and at $90^{\circ} \mathrm{C}$ was $50 \mathrm{~g}$. At the beginning of each experiment the $\mathrm{NaOH}$ charge was $2.5 \%$ (on oven-dry pulp). A $1 \%$ charge (on oven-dry pulp) of $\mathrm{MgSO}_{4}$ was also added at this time to ensure optimum stabilization of the carbohydrates. The pulp was mixed with the chemicals and placed in the preheated reactor. After reaching $90^{\circ} \mathrm{C}$, oxygen pressure was applied. At the end of the desired reaction time the pressure was released, the reactor opened, and the pulp was discharged and filtered. The spent liquor was collected and the pulp was washed thoroughly with de-ionized water. For the second and third stages the washed pulp was remixed with the same amount of fresh chemicals and loaded into the preheated reactor using the same procedure and conditions described above. Kappa no., viscosity, and Klason lignin contents of the pulps were measured according to the PAPTAC standard methods (22).

\section{Homogeneous oxidation of spent liquor}

The spent liquor from a 20-min oxygen delignification stage was collected, filtered without dilution, and placed in a glass-lined $1 \mathrm{~L}$ Parr reactor. To avoid metal ion contamination all interior parts of the reactor were coated with Teflon ${ }^{\circledR}$. The system was then heated to $90^{\circ} \mathrm{C}$ and an oxygen pressure of $0.68 \mathrm{MPa}$ was applied upon reaching temperature. The time of oxidation at temperature and pressure was 60 min with continuous mixing. After the treatment, the solubilized lignin was isolated according to the procedure 
Table 1. Oxygen delignification data characterizing the pulp at single and multiple oxygen stages and the residual lignins isolated.

\begin{tabular}{|c|c|c|c|c|c|c|c|}
\hline \multirow[b]{2}{*}{$\begin{array}{l}\text { Total delignification } \\
\text { time (min) }\end{array}$} & \multirow{2}{*}{$\begin{array}{l}\text { Kappa no. (Klason } \\
+ \text { UV lignin } \\
\text { content }(\%))\end{array}$} & \multirow[b]{2}{*}{$\begin{array}{l}\text { Viscosity } \\
\text { (mPa s) }\end{array}$} & \multirow{2}{*}{$\begin{array}{l}\text { Residual } \\
\text { lignin } \\
\text { yield }(\%)\end{array}$} & \multicolumn{4}{|c|}{ Lignin elemental analysis data (\%) } \\
\hline & & & & $\mathrm{C}$ & $\mathrm{H}$ & $\mathrm{N}$ & $\mathrm{OCH}_{3}$ \\
\hline \multicolumn{8}{|c|}{ One-stage oxygen delignification } \\
\hline 0 (initial pulp) & $30.0(4.3)$ & 42.0 & 68 & 60.0 & 5.7 & 0.71 & 11.6 \\
\hline 10 & $23.2(3.6)$ & 37.0 & 56 & 59.7 & 5.8 & 1.00 & 12.1 \\
\hline 20 & $20.6(3.0)$ & 35.0 & 61 & 60.4 & 5.9 & 1.33 & 9.8 \\
\hline 160 & $14.7(1.8)$ & 28.3 & 65 & 58.1 & 5.6 & 1.84 & 9.0 \\
\hline \multicolumn{8}{|c|}{ Multistage oxygen delignification } \\
\hline $60(20+20+20)^{a}$ & $13.4(1.4)$ & 28.5 & 69 & 54.5 & 5.5 & 2.64 & - \\
\hline $160(20+20+120)^{b}$ & $12.5(1.1)$ & 26.6 & 62 & 55.7 & 5.5 & 1.95 & - \\
\hline
\end{tabular}

${ }^{a}$ Three-stage $60 \mathrm{~min}$ delignificaiton comprised of three 20 -min individual stages.

${ }^{b}$ Three-stage 160 min delignification comprised of two 20-min and one 120-min individual stages.

described in ref. 27 , ensuring that the yields of lignin recovery were near quantitative.

\section{Lignin isolation}

Solubilized lignins were precipitated from the spent liquor by acidification with $1 \mathrm{M}$ solution of $\mathrm{HCl}$ to $\mathrm{pH} 1.5$. The precipitated lignin was then centrifuged, washed repetitively with acidified water $(\mathrm{pH} 2.0)$, and freeze-dried.

The residual lignins were isolated using a method recently developed in our laboratory (23). The method initially requires a mild enzymatic hydrolysis step with cellulase. The solubilized lignin was then precipitated by acidification and combined with the undissolved residue remaining after the enzymatic treatment. This mixture was then subjected to a very mild acidolytic treatment $(0.05 \mathrm{M}$ of $\mathrm{HCl}$ solution in dioxane-water (85:15) mixture). The lignin-containing solution was acidified with $1 \mathrm{M} \mathrm{HCl}$ to $\mathrm{pH} 2.0$, the precipitated lignin was then centrifuged, repetitively washed with $0.01 \mathrm{M}$ $\mathrm{HCl}$, and freeze-dried. At the end of the isolation procedure the lignin was extracted with dichloromethane to remove accumulated extractives. The yield of the extracted lignin ranged from 55 to $70 \%$ (Table 1). The protein contamination was calculated based on the nitrogen content (Table 1) and further calculations of functional groups content within the residual lignin were made taking this into account. Elemental and methoxyl analyses were carried out by the Schwarzkopf Microanalytical Laboratories, Woodside, New York.

\section{Oxidation of lignin model compounds}

Two lignin model compounds were oxidized: 4-methylphenol ( $p$-cresol) and 2-methoxy-4-methylphenol. Both compounds were purchased from Aldrich and used without purification. In preparation for the oxidation process, $p$ cresol $(0.54 \mathrm{~g}, 0.005 \mathrm{~mol})$ and 2-methoxy-4-methylphenol $(0.69 \mathrm{~g}, 0.005 \mathrm{~mol})$ were dissolved in $0.625 \mathrm{M} \mathrm{NaOH}$ $(250 \mathrm{~mL})$. The mixture was then placed in a glass-lined Parr reactor and oxidized at an oxygen pressure of $0.68 \mathrm{MPa}$ at $90^{\circ} \mathrm{C}$ for $60 \mathrm{~min}$ with continuous agitation. After the treatment an internal standard (3,4-dimethylphenol) (0.154 g, $0.001 \mathrm{~mol})$ was added, the mixture was acidified with $2 \mathrm{M}$ $\mathrm{HCl}$ to $\mathrm{pH} 2.0$ and repetitively extracted with ethylacetate.
The combined extracts were then dried over $\mathrm{MgSO}_{4}$ and quantitatively analyzed using a Hewlett-Packard HP 5890A gas chromatograph, equipped with a DB $530 \mathrm{~m} \times 0.25 \mathrm{~mm}$ packed silica capillary column (film thickness $0.25 \mu \mathrm{m}$ ) and a flame ionization detector. The injection port temperature was $280^{\circ} \mathrm{C}$ and the oven temperature was raised from $70^{\circ} \mathrm{C}$ to $200^{\circ} \mathrm{C}$ with a gradient of $15^{\circ} \mathrm{C} \mathrm{min}^{-1}$.

\section{NMR spectroscopy}

Quantitative ${ }^{31} \mathrm{P}$ NMR spectra of the lignins were acquired using a Varian Unity 500 spectrometer operating at 202.3 MHz according to the method described by Granata and Argyropoulos (24). Prior to the analysis the lignin was phosphitylated with 2-chloro-4,4,5,5-tetramethyl-1,3,2dioxaphospholane and cholesterol was employed as an internal standard. An inverse gated decoupling sequence was employed with a pulse width of $90^{\circ}$ and a relaxation delay between pulses of $5 \mathrm{~s}$. About 300 transients were acquired to ensure high signal-noise ratio. For each lignin sample at least two spectra were recorded to ensure reproducibility with low standard error. The spectra were integrated and the amounts of the different functional groups were calculated as described elsewhere (24).

Quantitative ${ }^{13} \mathrm{C}$ NMR spectra of the lignins were acquired on a Varian Unity 500 NMR spectrometer operating at $125.7 \mathrm{MHz}$ with an inverse gated decoupling sequence using a newly developed acquisition protocol described by Zia et al. (25). The weighed amount of lignin (400-450 mg) was placed into a $10 \mathrm{~mm}$ (o.d.) NMR tube and dissolved in DMSO- $d_{6}(2.7 \mathrm{~mL})$. A measured amount of 1,3,5-trioxane (30-35 mg) was added as an internal standard and $\mathrm{Cr}(\mathrm{acac})_{3}$ $(2 \mathrm{mg})$ was added as a relaxation agent. The sweep width of the spectra was $59970 \mathrm{~Hz}$, the pulse width was $14.1 \mu \mathrm{s}$, and the relaxation delay was $12.5 \mathrm{~s}$. For each spectrum about 7000-8000 scans were accumulated. The resulting spectra were integrated and the integrals compared with those of the internal standard as described elsewhere (25).

One-bond ${ }^{13} \mathrm{C}-{ }^{1} \mathrm{H}$ heteronuclear quantum coherence (HMQC) correlation spectra were recorded using a Varian Unity 500 NMR spectrometer with a $5 \mathrm{~mm}$ inverse geometry probe. To record the spectra $100 \mathrm{mg}$ of lignin was dissolved in $0.7 \mathrm{~mL}$ of DMSO- $d_{6}$ in a $5 \mathrm{~mm}$ (o.d.) sample tube. The 
spectra were acquired using 170 scans over 256 increments of $2 \mathrm{~K}$ data points over $10 \mathrm{ppm}$ in $\mathrm{F} 2\left({ }^{1} \mathrm{H}\right)$ and $140 \mathrm{ppm}$ in $\mathrm{F} 1\left({ }^{13} \mathrm{C}\right)$. To suppress the ${ }^{1} \mathrm{H}-{ }^{13} \mathrm{C}$ magnetization, a BIRD presaturaration sequence was used. The polarization transfer delay between ${ }^{1} \mathrm{H}$ and ${ }^{13} \mathrm{C}$ was set to $140 \mathrm{~Hz}$ and the relaxation delay was $0.8 \mathrm{~s}$. After processing with F1 zero filling, $\pi / 2$ shifted squared sinebell apodization and Fourier transformation were applied. The resulting matrix was $1024(\mathrm{~F} 2)$ $\times 1024(\mathrm{~F} 1)$ real points.

\section{Analytical pyrolysis (Py-GC-MS)}

The isolated residual lignin sample $(0.5 \mathrm{mg})$ was placed into the pyrolysis chamber of a pyroprobe 2000 (Chemical Data System) and purged with helium through the chamber for $10 \mathrm{~s}$ prior to pyrolysis to minimize oxidation. The interface starting temperature was $250^{\circ} \mathrm{C}$. The temperature was then increased at a rate of $20^{\circ} \mathrm{C} \mathrm{ms}^{-1}$ to $550^{\circ} \mathrm{C}$, and it was held at this temperature for $10 \mathrm{~s}$. The GC-MS analyses were carried out on a Hewlett-Packard 5972 mass spectrometer interfaced to a Hewlett-Packard HP 5890A gas chromatograph equipped with a DB-5 $30 \mathrm{~m} \times 0.25 \mathrm{~mm}$ packed silica capillary column with a film thickness of 0.25 $\mu \mathrm{m}$. The column temperature was held at $70^{\circ} \mathrm{C}$ for $4 \mathrm{~min}$ and it was then increased by $4^{\circ} \mathrm{C} \mathrm{min}^{-1}$ to $280^{\circ} \mathrm{C}$. The pyrolysis products were identified by their mass spectra fragmentation pattern. The relative content of $p$-hydroxyphenyl structures was calculated as a ratio of peak area assigned to these structures, to the total peak area.

\section{Results and discussion}

The lignin content in the oxygen-delignified pulp and the elemental analysis of the isolated residual and spent liquor lignins are shown in Table 1. The pulp and spent liquors were sampled at different intervals within a 160-min first stage delignification and at the end of a 60-min $(3 \times 20)$ three-stage and also a 120 -min $(2 \times 20$ and $1 \times 120)$ threestage process. During this effort the residual lignin was isolated using a mild enzymatic hydrolysis protocol, followed by a mild acidolytic treatment (23). In this novel isolation procedure the primary cellulolytic treatment digests most of the carbohydrates thus exposing the residual lignin and the mild acidolytic treatment ensures minimum secondary condensation reactions. This method supplies an excellent yield of residual lignins even for heavily oxidized pulps, i.e., an oxygen-delignified pulp after three stages (about 62 to $63 \%$, Table 1). More details of the procedure and detailed lignin analyses and purity data have been described by Argyropoulos et al. (23). This represents a major improvement over previous reports that implied that conventional methods of enzymatic hydrolysis could not provide an acceptable yield for such heavily oxidized pulps (26).

The isolated lignins were studied using a broad range of NMR spectroscopic techniques, namely quantitative ${ }^{31} \mathrm{P}$ NMR, ${ }^{13} \mathrm{C}$ NMR, and 2D heteronuclear (HMQC) NMR spectroscopy. Quantitative information on the different types of functional groups in the lignins was collected and analyzed to follow the changes occurring within the kraft pulp lignin during multistage oxygen delignification.

The kappa no. measured after various time intervals of the oxygen delignification shows that after 50-60 min of oxida- tion the delignification had significantly slowed. Attempts to use a multistage approach only marginally reduced the lignin content (to kappa no. 12.5) (representing about $60 \%$ delignification). As anticipated, the introduction of the multistage approach showed no significant improvement in the effectiveness of oxygen delignification, in agreement with various large scale industrial operations (7). Recent claims by industry suppliers in relation to extending these limits, most likely, rest with lignin leaching effects at the second stage and not on actual degradation by oxygen (6).

\section{The role of phenolic hydroxyl groups}

Most early efforts attempted to unravel the mechanism of oxygen delignification using lignin model compounds (9, 10). These studies suggested that the reactivity of the phenylpropane units bearing free phenolic hydroxyl groups far surpassed that of non-phenolic structures. To this effect Gierer (14) regards the role of free phenolic units as the centers of radical formation. Consequently, amongst all the lignin functional groups we focused our attention on the free phenolic hydroxyl groups because of the evidence pointing to their important role in the chemistry of oxygen delignification.

In two earlier accounts the extreme depletion of phenolic groups during oxygen delignification has been cited as the factor responsible for the limits of the process $(15,16)$. Chirat et al. (26) and Johansson and Ljunggren (12) however, reported that the decrease of the amount of free phenolic hydroxyls is significant but even after extensive multistage delignification there is still an abundance of such groups within the lignin. In addition, our earlier research on oxidation of isolated residual kraft lignin (27), pointed out that even under extreme and idealized oxidation conditions $\left(140^{\circ} \mathrm{C}, 80 \mathrm{~min}\right.$, homogeneous solution, and thorough mixing) about $50 \%$ of the initial amount of the total phenolic $\mathrm{OH}$ remained within the lignin structure. Our data was also later supplemented and supported by that of Moe and Ragauskas (28) who showed free phenolic hydroxyl content within residual kraft lignin decreased by only about $30-40 \%$ after oxygen delignification.

The amount of phenolic hydroxyls present in the residual lignin of oxidized kraft pulp was determined by quantitative ${ }^{31} \mathrm{P}$ NMR spectroscopy (Table 2). The residual lignins isolated from the delignified pulps show a rapid depletion of the total free phenolic hydroxyl units during the initial $10 \mathrm{~min}$ of oxygen delignification from 1.87 to $1.42 \mathrm{mmol} \mathrm{g}^{-1}$, which represents a $24 \%$ decline. Then after 50 min of treatment, the amount of the phenolic hydroxyl units was seen to stabilize at approximately $60 \%$ and did not further decrease (Fig. 1). Application of three stages of delignification with thorough interstage washing did not result in any significant additional decrease of the phenolic hydroxyl level (Table 2). More specifically, even after two 20-min stages and a third 120 -min stage the amount of phenolic units within the resid-

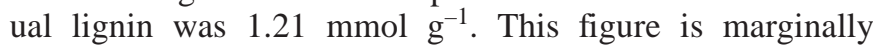
lower than the corresponding amount within the residual lignin from the pulp delignified in a single 160-min stage $\left(1.31 \mathrm{mmol} \mathrm{g}^{-1}\right)$.

While it is very likely that the decrease of phenolic $\mathrm{OH}$ units is a consequence of lignin oxidation reactions, our data indicates that factors other than the lack of phenolic $\mathrm{OH}$ 
Table 2. Phenolic group content $\left(\mathrm{mmol} \mathrm{g}^{-1}\right)$ in lignins isolated from pulp and spent liquor after oxygen deliginification as determined by quantitative ${ }^{31} \mathrm{P}$ NMR spectroscopy.

\begin{tabular}{|c|c|c|c|c|c|}
\hline $\begin{array}{l}\text { Time of } \\
\text { treatment }(\mathrm{min})\end{array}$ & $\begin{array}{l}\text { Non-condensed } \\
\text { guaiacyl units }\end{array}$ & $\begin{array}{l}\text { Total condensed } \\
\text { units }^{b}\end{array}$ & $\begin{array}{l}\text { 5,5' Condensed } \\
\text { units }^{c}\end{array}$ & $\begin{array}{l}p \text {-Hydroxy- } \\
\text { phenyl units }{ }^{d}\end{array}$ & $\begin{array}{l}\text { Total free } \\
\text { phenolic units }\end{array}$ \\
\hline \multicolumn{6}{|c|}{ Solubilized lignins in spent liquor } \\
\hline 20 & 0.65 & 0.87 & 0.47 & - & 1.52 \\
\hline 50 & 0.56 & 0.81 & 0.44 & - & 1.37 \\
\hline 80 & 0.49 & 0.80 & 0.43 & - & 1.29 \\
\hline $20+20+20^{f}$ & 0.40 & 0.77 & 0.51 & - & 1.17 \\
\hline $20+20+120^{f}$ & 0.25 & 0.58 & 0.37 & - & 0.83 \\
\hline \multicolumn{6}{|c|}{ Residual lignins in pulp } \\
\hline 0 & 0.87 & 0.96 & 0.44 & 0.04 & 1.87 \\
\hline 10 & 0.63 & 0.69 & 0.34 & 0.10 & 1.42 \\
\hline $20+20+20^{f}$ & 0.48 & 0.75 & 0.46 & 0.18 & 1.41 \\
\hline $20+20+120^{f}$ & 0.34 & 0.73 & 0.44 & 0.14 & 1.21 \\
\hline
\end{tabular}

groups cause the oxygen delignification to reach a ceiling. Our continuing efforts to locate these factors prompted further investigation of the structural features of isolated residual lignins.

\section{The role of condensation reactions}

In earlier work we demonstrated that under homogeneous oxidative conditions the rate of elimination of condensed phenolic units in residual kraft lignin was slower than the rate of elimination of uncondensed guaiacyl phenolic units (21). Amongst the condensed structures, 5,5' biphenolic structures showed the highest resistance. They decreased in the initial phase of oxidation but after about 40 min of treatment their content did not further decrease. This resulted in a significant accumulation of the condensed hydroxyl content within the oxidized residual lignin (21). The origin of $5,5^{\prime}$ biphenolic moieties in kraft lignin are the eightmembered dibenzodioxocins ring structures recently discovered by Brunow and co-workers (29). Recent work in our laboratory has shown that they constitute about $10 \%$ of the phenyl propane units in lignin, or about 10 such rings are present per 100 phenyl propane units $(30,31)$. Dibenzodioxocins, under kraft pulping conditions open quantitatively to release large amounts of 5,5' biphenolic moieties, making the presence of these units abundant in residual kraft lignin (31).

Consequently, we paid particular attention to the behavior of the condensed phenolic structures, and more specifically on the development of $5,5^{\prime}$ biphenyl structures within the residual lignins as a function of intensity of oxygen delignification. Within the solubilized lignins the condensed
Fig. 1. Total phenolic hydroxyl group content measured in isolated residual lignin at various intervals along an oxygen delignification process.

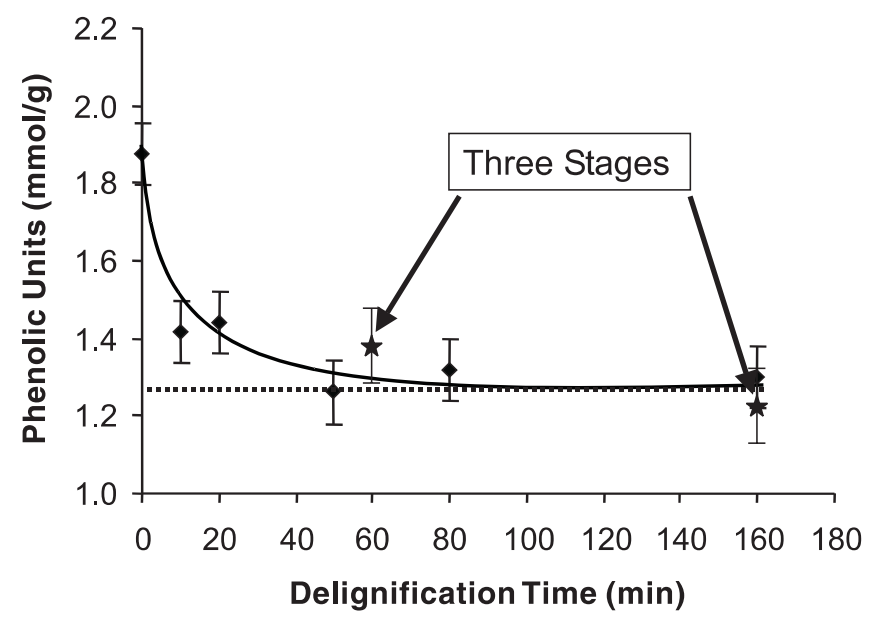

phenolic $\mathrm{OH}$ content was found to decrease by about 25$30 \%$ during the initial stages of delignification $(20 \mathrm{~min})$ and then remained essentially constant (Table 2). In the residual lignins, however, the 5,5' biphenolic condensed structures were found to decrease from 0.44 to $0.38 \mathrm{mmol} \mathrm{g}^{-1}$ during the early phases of oxygen delignification, and then started to build up again to a value of $0.49 \mathrm{mmol} \mathrm{g}^{-1}$ level (Fig. 2a). However, when the liquor coexisting with the pulp was replaced in a series of multistage experiments, the content of 
Fig. 2. 5,5'-Biphenyl moieties present within the residual lignin at various points along a conventional oxygen delignification process. The upper plot $(2 a)$ shows the data derived from quantitative ${ }^{31} \mathrm{P}$ NMR of analyses of the lignins, while the lower plot (2b) shows the data for the same moieties derived from quantitative ${ }^{13} \mathrm{C}$ NMR analyses.

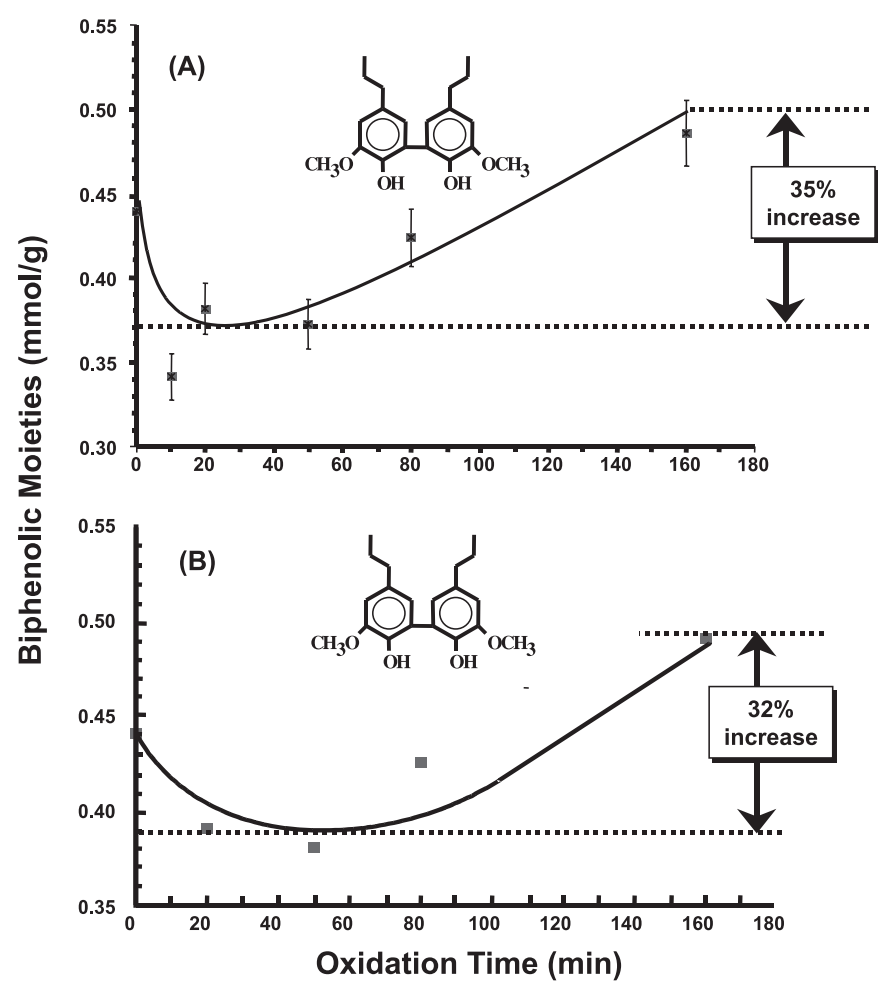

5,5' biphenyls did not increase. Even after a prolonged three-stage delignification the level of $5,5^{\prime}$ hydroxyls remained at $0.44 \mathrm{mmol} \mathrm{g}^{-1}$, which is lower than the $0.49 \mathrm{mmol}$ $\mathrm{g}^{-1}$ level reached in the corresponding one-stage oxygen delignification (Table 2).

In an effort to further support our measurements of 5,5' biphenolic structures we measured them using an independent method. For this purpose we developed a quantitative ${ }^{13} \mathrm{C}$ NMR protocol (25) (using an internal standard) and as such we were able to measure the precise amounts of 5,5' etherified and non-etherified biphenyl moieties and their development within residual oxidized lignins as a function of the extent of oxidation. The data of Fig. $2 b$ confirmed that the content of non-etherified $5,5^{\prime}$ biphenyl structures after $80 \mathrm{~min}$ increased over the overall time scale of the oxidation. In addition, the etherified 5,5' structures were also seen to increase (Table 4, see C3 in the last column). The inert nature of such moieties under oxygen delignification conditions could be held responsible for this enrichment.

Our observations so far correlate well with earlier experiments attempting to understand the mechanism of oxygen delignification, using isolated residual kraft lignin oxidized under homogeneous conditions $(21,27)$. These accounts coupled with the present findings support the idea that the etherified and even non-etherified 5,5' biphenolic structures are unreactive under oxygen delignification conditions. The accumulation of these groups during oxygen delignification
Table 3. Relative content of $p$-hydroxyphenyl moieties present in the products of analytical pyrolysis of oxidized residual lignins (\%), as determined by oxygen delignification.

\begin{tabular}{cl}
\hline $\begin{array}{l}\text { Time of oxidation } \\
(\min )\end{array}$ & $\begin{array}{l}\text { Relative content of } \\
p \text {-hydroxyphenyl }(\%)\end{array}$ \\
\hline 0 & 2.3 \\
20 & 2.5 \\
50 & 3.4 \\
80 & 3.5 \\
160 & 4.0 \\
\hline
\end{tabular}

could be another factor imposing limits to the process while the role of lignin-carbohydrate linkages still remains unclear.

The observed increase of 5,5' biphenyl hydroxyls could be attributed to secondary condensation reactions. Such reactions, which are likely to occur between phenoxy radicals forming on the mobile solubilized fraction and the radicals forming on immobilized residual lignin could generate new 5, $5^{\prime}$ condensed structures. Earlier efforts in our laboratory have demonstrated and quantified that these coupling reactions occur with catechol and 3-methoxy-4-hydroxy toluene (32). These compounds were shown to produce significant quantities of 5,5' related products under oxidative conditions.

In an effort to further support and substantiate this rationalization we carried out the following series of experiments, schematically represented in Fig. 3.

After $20 \mathrm{~min}$ of pulp oxidation in the medium-consistency oxygen delignificaton reactor, the extracted liquor was quantitatively collected and further oxidized for an additional 60 min (without dilution) in a Parr reactor (see Fig. 3). After the oxidation, the lignin was recovered quantitatively and subjected to detailed analyses (Table 2). The amount of 5,5 condensed phenolic units formed by this liquor treatment in the absence of fiber were found to be $0.55 \mathrm{mmol} \mathrm{g}^{-1}$. This figure was found to be $22 \%$ higher than experiments where the fiber was present throughout the oxidation for a total treatment time of $80 \mathrm{~min}$ (Table 2).

It is thus reasonable to assume that phenols liberated from the lignocellulosic matrix could form highly mobile and reactive radicals which may recombine with similar moieties present on the fiber. This process could lead to the formation of new 5,5' unreactive biphenolic moieties present on the fibre, explaining the ${ }^{31} \mathrm{P}$ and ${ }^{13} \mathrm{C}$ NMR data of Fig. 2 and Table 3 , respectively.

\section{Noncondensed phenolic hydroxyls}

Other functional groups that require attention are the noncondensed phenolic hydroxyls. Studies with lignin model compounds $(12,33)$ and residual lignin have shown that under oxygen delignification conditions such moieties are much more reactive than biphenyl structures (20).

The noncondensed guaiacyl units in the solubilized lignins decreased monotonically from 0.85 (at $10 \mathrm{~min}$ ) to $0.25 \mathrm{mmol} \mathrm{g}^{-1}$, as the delignification time was extended and the oxidation intensified (Table 2). However, the changes that occurred to the noncondensed phenolic moieties were different within the residual lignin. As delignification proceeded, the guaiacyl phenolic hydroxyl content in the residual 
Fig. 3. A schematic showing the series of experiments carried out aimed at confirming the occurrence of $5,5^{\prime}$ linkages between mobile phenoxy radicals and immobilized residual fibre lignin.

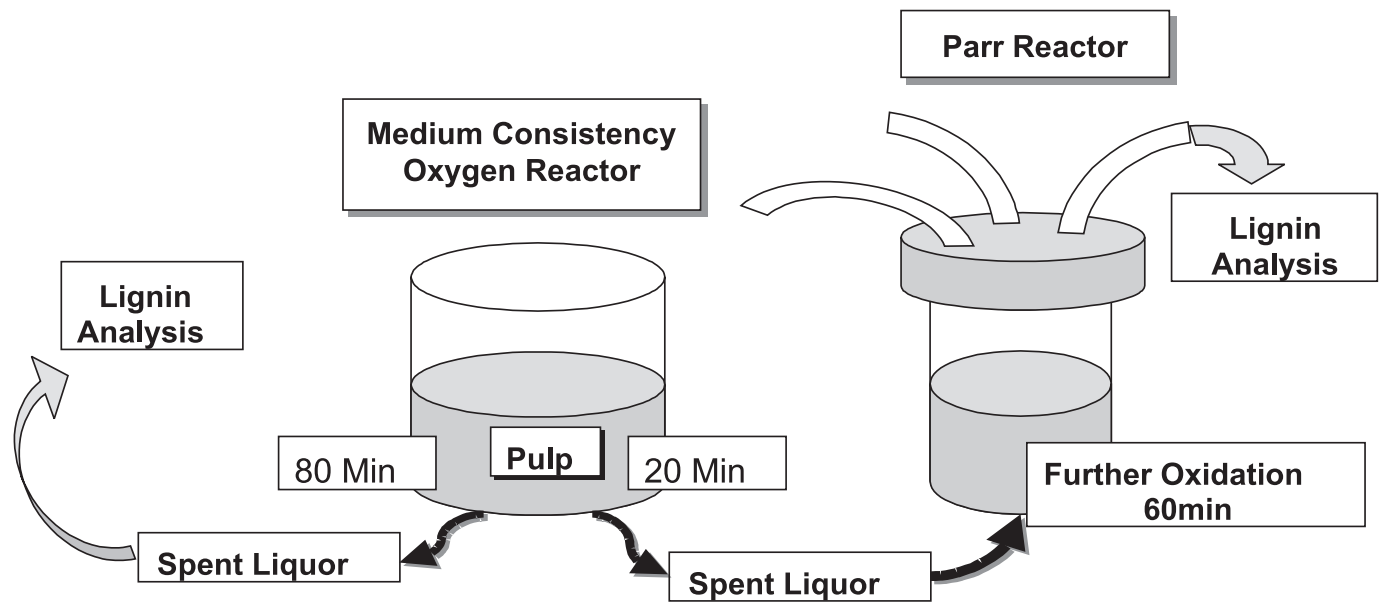

lignin also decreased but in a different fashion (Table 2). During the initial rapid phase of delignification the level of noncondensed phenols within the residual lignin was reduced by about 50\%. This level was then maintained throughout the rest of the process irrespective of the intensity of oxidation. Only after a series of prolonged delignification stages, one may observe a decrease of these moieties to about $40 \%$ of the initial level.

Based on these data it is clear that noncondensed units bearing free phenolic hydroxyls possess excellent reactivity under oxygen delignification conditions. However, the fact that the delignification stops well in advance from the total depletion of these units casts a reasonable doubt to the claim that their depletion is responsible for the ceiling of oxygen delignification.

\section{Accumulation of $\boldsymbol{p}$-hydroxyphenyl units}

A comparison of the HMQC (one-bond ${ }^{13} \mathrm{C}-{ }^{1} \mathrm{H}$ correlation technique, which displays the signals of carbon atoms directly linked to protons) NMR spectra of the initial residual lignin and the sample isolated after $80 \mathrm{~min}$ of delignification (Fig. 4) revealed that a new group of signals appeared in the spectra of the oxidized lignin. These signals appear in the downfield region assigned to aromatic nuclei (Fig. 4, region B) characteristic of $p$-hydroxyphenyl structures (34) while region A is characteristic of guaiacyl correlations. In the spectrum of residual kraft lignin (Fig. 4) before oxidation the $p$-hydroxyphenyl signals are below the detection limit and could not be identified.

To further confirm and quantify the presence of these structures within the residual lignin we examined the quantitative ${ }^{31} \mathrm{P}$ NMR spectra of the isolated residual lignins. The $p$-hydroxyphenyl $\mathrm{OH}$ gives rise to a well-resolved peak at $137.8 \mathrm{ppm}$ in the spectra of the oxidized lignin (35). As such their amount within the residual lignin was quantified and was shown to progressively increase by more than three-fold during oxygen delignification (from $0.04 \mathrm{mmol} \mathrm{g}^{-1}$ at 0 min to $0.15 \mathrm{mmol} \mathrm{g}^{-1}$ at $160 \mathrm{~min}$ (Table 2, Fig. 5)). When the content of these structures was calculated on a per $g$ of pulp basis it was found that their content remained essentially constant throughout the delignification process. This clearly
Fig. 4. HMQC spectra and specific signal assignments for residual lignin isolated from a pulp before and after 80 min of oxygen delignification. Where: (a) 4-hydroxy-3-methoxyphenol correlations and $(b)$ p-hydroxyphenyl correlations.

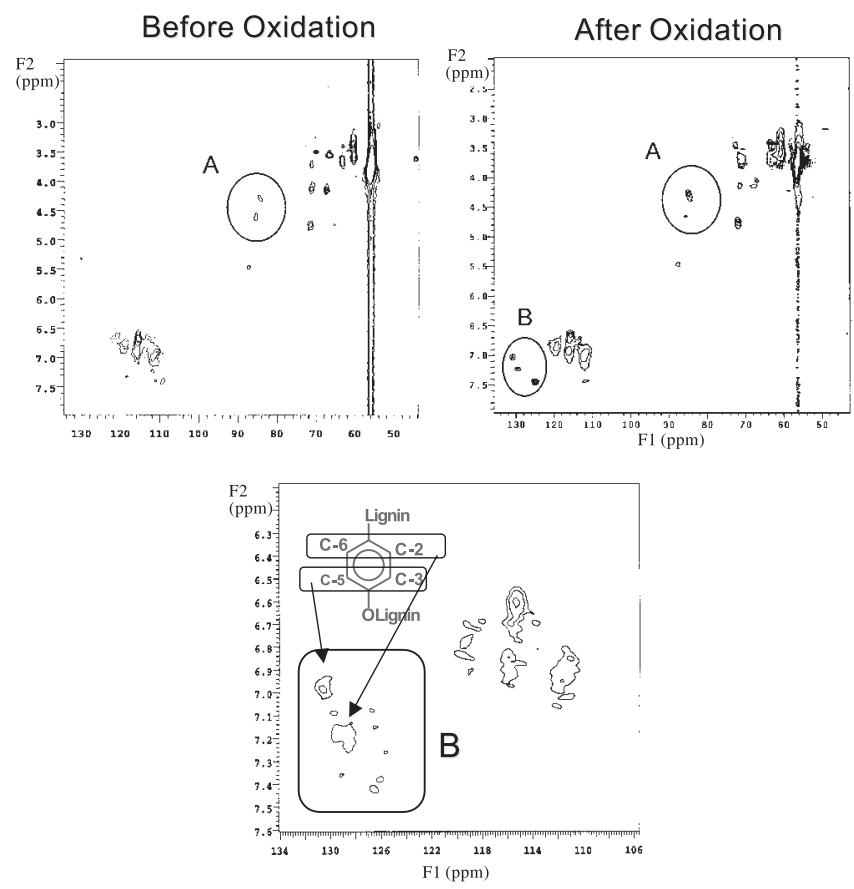

indicates that these units accumulate and do not form during oxygen delignification.

A series of isolated residual lignin samples was subjected to further analyses using a combination of analytical pyrolysis coupled to a gas chromatographic and a mass spectroscopic detector (Py-GC-MS). The results in Table 4 show that the relative content of p-hydroxyphenyl units within the pyrolysis products increased with increasing delignification time.

It is a known fact that softwood lignin contains small amounts of $p$-hydroxyphenyl units. Estimates for their abundancy vary from 5\% (Picea abies (36)) to 13\% (Pinus taeda (37)). If $p$-hydroxyphenyl units survive oxygen 
Table 4. Quantitative structural information for residual oxidized lignins obtained by ${ }^{13} \mathrm{C}$ NMR spectroscopy $\left(\mathrm{mmol}^{-1}\right)$.

\begin{tabular}{|c|c|c|c|c|c|c|}
\hline \multirow{2}{*}{$\begin{array}{l}\text { Spectral range } \\
(\mathrm{ppm})\end{array}$} & \multirow{2}{*}{ Assignment } & \multicolumn{5}{|c|}{ Delignification time (min) } \\
\hline & & 0 & 20 & 80 & 160 & $80^{b}$ \\
\hline $154.8-150.2$ & $\mathrm{C} 3$ in $\mathrm{G}^{a}$ (5-5'etherified) & 0.67 & 0.73 & 0.83 & 0.88 & 0.92 \\
\hline $140.1-122.6$ & $\mathrm{C} 1$ in $\mathrm{G}$; $\mathrm{C} 5$ in $\mathrm{G}(5$-condensed $)$; $\mathrm{C} 2,6$ in $\mathrm{H}$ & 8.69 & 6.46 & 6.73 & 7.04 & 8.36 \\
\hline $122.6-105.1$ & $\mathrm{C} 2,5,6$ in $\mathrm{G} ; \mathrm{C} 3,5$ in $\mathrm{H}$ & 9.67 & 7.21 & 6.84 & 6.63 & 7.69 \\
\hline $154.8-105.1$ & Total Aromatic & 27.6 & 20.1 & 20.5 & 20.6 & 23.4 \\
\hline $58.2-54.2$ & $\mathrm{OCH}_{3}$ (calculated in $\%$ weight) & $4.05(12.5)$ & $3.62(11.2)$ & $3.10(9.6)$ & $2.80(8.6)$ & $3.04(9.4)$ \\
\hline - & $\mathrm{OCH}_{3}$ (elemental analysis data) & 11.7 & 9.8 & 8.8 & & - \\
\hline
\end{tabular}

${ }^{a} \mathrm{G}=$ guaiacyl units, $\mathrm{H}=p$-hydroxyphenyl units.

${ }^{b}$ Solubilized lignin after $80 \mathrm{~min}$ of the delignification.

${ }^{c}$ Sum of the amount of $\mathrm{C} \alpha$ and $\mathrm{C} \beta$ atoms was divided by two to show the amount of $\beta-O-4$ units.

${ }^{d}$ Data are not reliable due to carbohydrate contamination.

Fig. 5. $p$-Hydroxyphenyl $\mathrm{OH}$ content in the residual lignin at various points along a conventional oxygen delignification process.

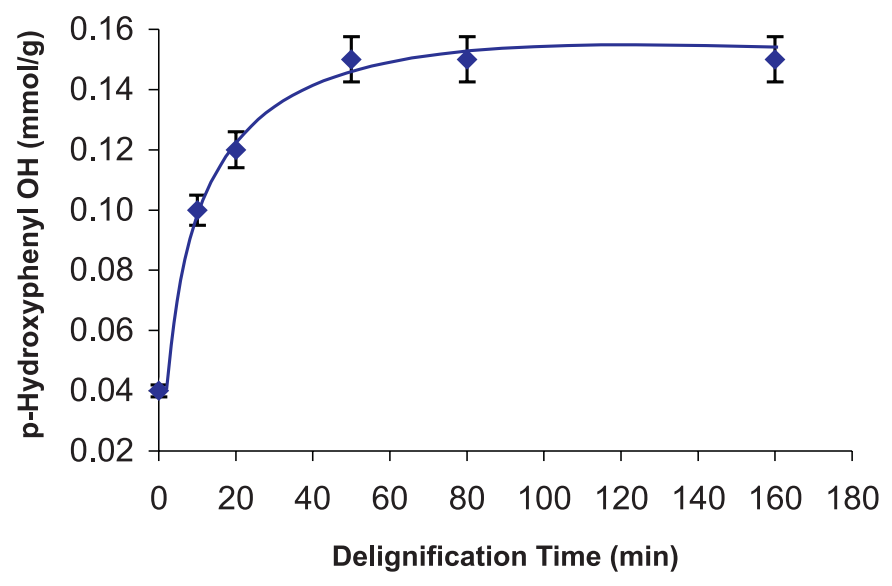

delignification, or at least undergo only limited degradation compared to the guaiacyl units, such moieties may accumulate within the residual lignin. Additional support of this contention arises from literature accounts claiming the accumulation of $p$-hydroxyphenyl units during the process of oxidative delignification with peroxyacids or laccase-mediator systems $(38,39)$.

Since three independent analytical techniques corroborate the presence and accumulation of such units within the oxygen delignified pulp, this represents convincing evidence for their presence and role in the process. Unfortunately, however there are no literature accounts of directly comparing the oxidative reactivity of $p$-hydroxyphenyl structures with their guaiacyl counterparts. To address this issue we designed a set of experiments where two model compounds, namely: 4-hydroxy toluene and its guaiacyl counterpart (3methoxy-4-hydroxy toluene) were oxidized under conditions resembling those of oxygen delignification. The products of the oxidation were then quantified by gas chromatography. It was found that $45 \%$ of 4-hydroxy toluene remained unreacted while only $12 \%$ of the guaiacyl phenol remained in the reaction mixture. This experiment demonstrated the higher stability of $p$-hydroxyphenyl moieties under oxygen delignification conditions. This provides additional evidence that their accumulation contributes to impairing the rate of the process as oxidation intensifies. Since considerably higher amounts of $p$-hydroxyphenyl units exist in hardwood than in softwood, the accumulation of such units could be even more pronounced during oxygen delignification of hardwood pulps. This may, in part, explain the tendency of hardwood pulps to be more difficult than softwood pulps to delignify with oxygen (4).

\section{Other lignin structural changes}

The quantitative ${ }^{13} \mathrm{C}$ NMR spectra of the residual lignins isolated from the pulp at different oxidation times are shown in Fig. 6.

Notably, these spectra were similar to those of an oxidized residual lignin recently published by Gellerstedt et al. (40). The only visible difference is the peak at $171.8 \mathrm{ppm}$ assigned to carboxylic carbon atoms. This peak significantly increases as the time of delignification increases. This increase correlates well with the amount of protein contaminants present in the residual lignins and could be attributed to signals of amidic carbonyl group present in proteins. A group of signals due to $p$-hydroxyphenyl structures and probably signals from olefinic carbons at $130.2-129.3 \mathrm{ppm}$, also progressively increased in size as the oxidation intensified.

A comparison of the ${ }^{13} \mathrm{C}$ spectra of Fig. 6 brings to light that all the changes in the residual lignin structure are of a quantitative rather than qualitative character. In this respect, our quantitative ${ }^{13} \mathrm{C}$ NMR acquisition conditions significantly facilitated the extraction of information and the comparison of the spectra.

There are a number of reports demonstrating that residual $\beta-O-4$ structures present within kraft lignin are stable under oxygen delignification conditions $(13,28,40)$. The signal area between 89.2-67.3 ppm was assigned to $\mathrm{C} \alpha$ and $\mathrm{C} \beta$ signals of the atoms involved in $\beta-O-4$ bonds based on our HMQC spectra and previous accounts (41). The data supplied by quantification of these areas showed that the abundancy of these moieties does not change during the initial $80 \mathrm{~min}$ of oxidation (Table 4), i.e., it remained at about $1.20 \mathrm{mmol} \mathrm{g}$. This amount decreased to $1.07 \mathrm{mmol} \mathrm{g}^{-1}$ when the total oxygen delignification time reached $160 \mathrm{~min}$. 
Fig. 6. Quantitative ${ }^{13} \mathrm{C}$ NMR spectra of residual lignins at various points along a conventional oxygen delignification process.

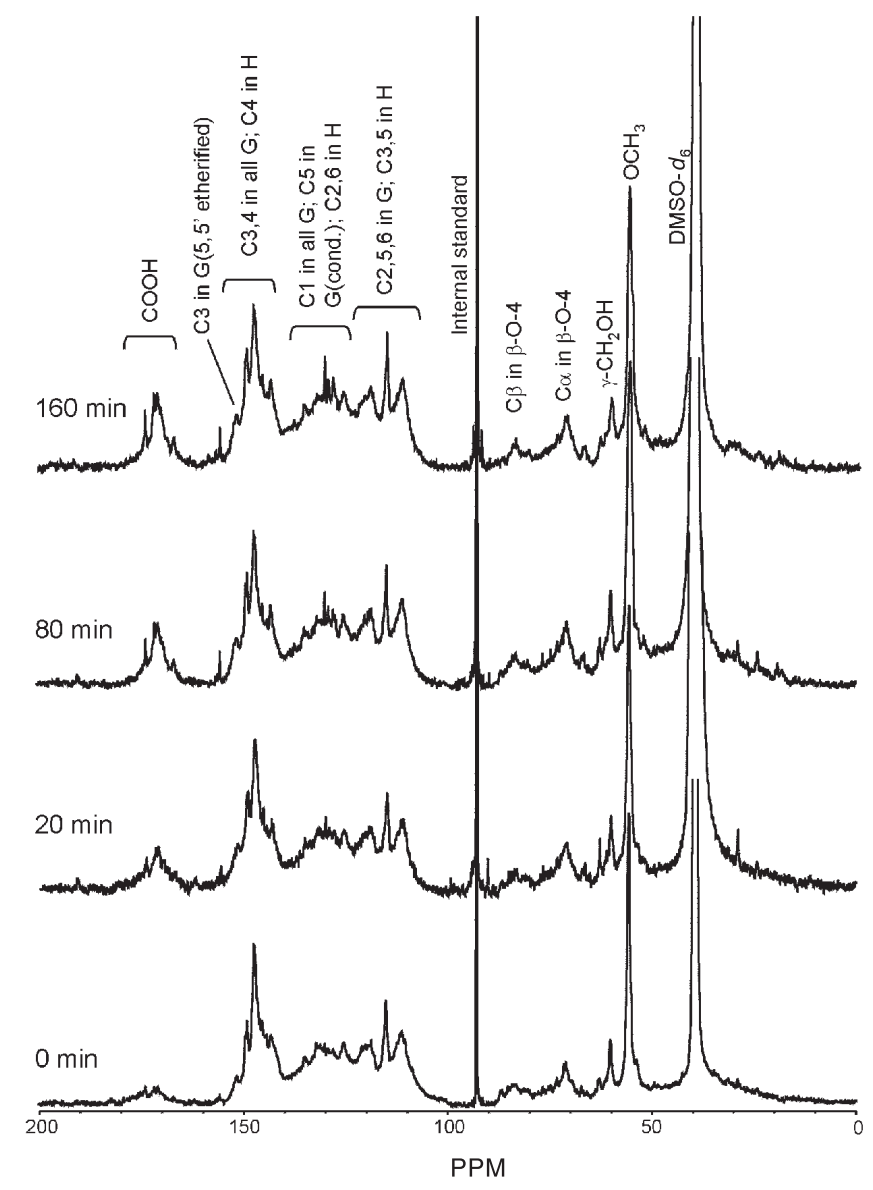

Under extensive oxygen delignification conditions the oxidative degradation of aliphatic side-chains may also become pronounced. This is confirmed by the amount of the $\gamma$ $\mathrm{CH}_{2} \mathrm{OH}$ groups which significantly decreased during the process (Table 4). A possible mechanism operating could be that of a reverse aldol condensation reaction causing $\gamma$-carbon elimination.

The methoxyl content of all residual oxidized lignins gradually decreased during oxygen delignification ranging from 4.1 to $2.8 \mathrm{mmol} \mathrm{g}^{-1}$ (Table 4). The difference between the two extreme values is about $32 \%$. This data correlate well with published accounts (16) and our elemental analyses data (Table 1) and can be rationalized on the basis of demethoxylation reactions occurring prior to aromatic ring cleavage $(11,27)$.

To further assess the differences between the solubilized and residual kraft lignins the quantitative ${ }^{13} \mathrm{C}$ NMR spectra of lignins isolated after $80 \mathrm{~min}$ of oxygen delignification were compared. Unfortunately, minor carbohydrate contaminants within the sample of the solubilized lignin prevented a reliable quantification of the aliphatic region. However, data obtained by quantification of the aromatic region (Table 4) revealed that at the same stage of oxygen delignification, (23.4 and $20.5 \mathrm{mmol} \mathrm{g}^{-1}$, respectively) the solubilized lignin was of higher aromaticity compared to its residual lignin counterpart.

\section{Conclusions}

A number of factors are responsible for imposing limits usually encountered in oxygen delignification. While phenolic hydroxyl groups are reactive under oxygen delignification conditions their presence is not essential for continuing reactivity at latter stages of the process. 5,5' Biphenyl structures are relatively inert toward oxidation and accumulate within the residual lignin. Radical coupling reactions are also likely to occur between phenoxy guaiacyl radicals in the liquor and on the fiber, resulting in the formation of $5,5^{\prime}$ structures. Considerably less reactive $p$-hydroxyphenyl structures were also observed to accumulate within the residual lignin. However, the nature of the linkage of the remaining lignin moieties to the fiber still remains unclear. The likelihood of lignin-carbohydrate linkages being formed during oxygen delignification, anchoring lignin moieties on the fibre is currently under investigation in our laboratory.

\section{Acknowledgments}

The authors would like to express their gratitude to $\mathrm{Mr}$. Ernst Palus and Mr. Tibor Kristof for their assistance with residual lignin isolation and pulp analyses. In addition, Dr. Anna-Stiina Jaaskelainen also deserves our gratitude for carrying out the Py-GC-MS analyses, Mr. Yujun Sun for participating in a number of valuable discussions, and Mrs. Barbara van Lierop for reviewing the manuscript.

\section{References}

1. T.J. McDonough. Tappi J. 78, 55 (1995).

2. L. Olin and A. Teder. Tappi J. 62, 43 (1979).

3. V. Masura. Cellul Chem. Technol. 27, 201 (1993).

4. T.J. McDonough. In Pulp bleaching. Principles and practice. Edited by C.W. Dence and D.W. Reeve. Tappi, Atlanta. 1996. pp. 213-239.

5. P. Liias, T. Merikallio, and T. Metsa-Rauma. In Proceedings of the International Pulp Bleaching Conference. Helsinki, Finland. 1998. pp. 269-274.

6. M. Bokström and S. Nordén. Extended oxygen delignification. In Proceedings of the International Pulp Bleaching Conference. Vol. 1. Helsinki, Finland. 1998. pp. 23-31.

7. R.W. Allison and S.W. Wrathall. In Proceedings of the International Pulp Bleaching Conference. Vol. 1. Helsinki, Finland. 1998. pp. 41-48.

8. C. Chirat and D. Lachenal. Limits of oxygen delignification. In Proceedings of the Tappi Pulping Conference. Vol. 1. Montreal, QC, Canada. 1998. pp. 619-704.

9. K. Kratzl, P. Claus, W. Lonsky, and J.S. Gratzl. Wood Sci. Technol. 8, 35 (1974).

10. K. Kratzl, J. Gratzl, and P. Claus. Adv. Chem. Ser. 59, 157 (1966).

11. S.J. Ljunggren. J. Pulp Paper Sci. 12, 54 (1986).

12. E. Johansson and S.J. Ljunggren. J. Wood Chem. Technol. 14, 507 (1994).

13. S. Ljunggren, G. Gellerstedt, and M. Petersson. Chemical aspects of the degradation of lignin during oxygen bleaching. In Proceedings of the 6th International Symposium on Wood and 
Pulping Chemistry. Vol. 1. Melbourne, Australia. 1991. pp. 229-235.

14. J. Gierer. Holzforsch. 51, 34 (1997).

15. G. Gellerstedt, K. Gustafsson, and E.L. Lindfors. Nordic Pulp Pap Res. J. 1, 14 (1986).

16. G. Gellerstedt, and L. Heuts. J. Pulp Pap. Sci. 23, 335 (1997).

17. B. Hortling, T. Tamminen, P. Tikka, and J. Sundquist. Structures of the residual lignins of modified kraft pulps compared with conventional and oxygen-bleached kraft pulps. In Proceedings of the 7th International Symposium on Wood and Pulping Chemistry. Vol. 1. Beijing, China. 1993. pp. 313-317.

18. Y. Sun and D.S. Argyropoulos. J. Pulp Pap. Sci. 21, 185 (1995).

19. E. Johansson, I.D. Suckling, and R.M. Ede. Effect of O and OO delignification on the structure of residual lignin from Pinus radiata pulp. In Proceedings of the 9th International Symposium on Wood and Pulping Chemistry. Vol. 1. Montreal, QC, Canada. 1997. pp. J1-1.

20. Y.-Z. Lai, M. Funaoka, and H.-T. Holzforsch. 48, 355 (1994).

21. D.S. Argyropoulos and Y. Liu. J. Pulp Pap. Sci. 26, 107 (2000).

22. PAPTAC Standards Methods: G.18, G.24P, G.8/G.9 PAPTAC (2000).

23. D.S. Argyropoulos, E. Palus, and Y. Sun. Isolation of residual kraft lignin in high yield and purity. Submitted for publication.

24. A. Granata and D.S. Argyropoulos. J. Agric. Food Chem. 43, 1538 (1995).

25. S. Zia, L.G. Akim, and D.S. Argyropoulos. Quantitative ${ }^{13} \mathrm{C}$ NMR of lignins with internal standards. Submitted for publication.

26. C. Chirat, D. Cardoba-Barrau, and D. Lachenal. Effect of oxygen on residual lignin: ways to improve lignin removal. In Proceedings of the 10th International Symposium on Wood and Pulping Chemistry. Vol. 1. Yokohama, Japan. 1999. pp. 238241.

27. F. Asgari and D.S. Argyropoulos. Can. J. Chem. 76, 1606 (1998).

28. S.T. Moe and A.J. Ragauskas. Holzforschung, 53(4), 416 (1999).

29. P. Karhunen, P. Rummakko, J. Sipila, G. Brunow, and I. Kilpelainen. Tetrahedron Lett. 36 (1995).
30. D.S. Argyropoulos, L. Akim, and B. Ahvazi. Salient reactions in lignin during pulping and bleaching. Proceedings of the Tappi Pulping Conference, Boston, Mass. Nov. 6-8, 2000. Vol. 143. Paper 54-1.

31. S.I. Tohmura and D.S. Argyropoulos. Determination of arylg1ycerol- $\beta$-aryl ethers and other linkages in native and technical lignins. J. Agric. Food Chem. 49, 155e2 (2000).

32. Y. Sun, M. Fenster, A. Yu, R.M. Berry, and D.S. Argyropoulos. Can. J. Chem. 77, 667 (1999).

33. S. Ljunggren and E. Johansson. Nordic Pulp Pap. Res. J. 5, 148 (1990).

34. D. Robert, D. Piersantelli, L. Jouanin, V. Ferret, B. Pollet, and C. Lapierre. ${ }^{13} \mathrm{C}$ NMR spectroscopy of lignins from transgenic poplars deficient in $O$-methytransferase and cinnamyl alcohol dehydrogenase. In Proceedings of the 10th International Symposium on Wood and Pulping Chemistry, Yokohama, Japan, 1999. Vol. III, pp. 18-21.

35. C. Crestini and D.S. Argyropoulos. J. Agric. Food Chem. 45, 1212 (1997).

36. M. Erickson, S. Larsson, and G.E. Miksche. Acta Chem. Scan. 27, 1675 (1973).

37. W.G. Glasser and H.R. Glasser. Pap. Puu, 63(2), 71 (1981).

38. K. Poppius-Levlin, T. Tamminen, K. Rajanen, and A.-S. Jääskeläinen. Suitability of laccase/mediator systems for hardwood kraft pulp delignification. In Proceedings of the 10th International Symposium on Wood and Pulping Chemistry, Yokohama, Japan, 1999, Vol. 1, pp. 556-561.

39. T. Tamminen, T. Elder, W. Wang, and K. Poppius-Levlin. Proceedings of the 7th International Conference On Biotechnology in the Pulp and Paper Industry, Vancouver, Canada, 1998, Vol. A, pp. A107-110.

40. G. Gellerstedt, L. Heuts, and D.J. Robert. J. Pulp Pap. Sci. 25, 111 (1999).

41. J. Ralph, J.M. Marita, S.A. Ralph, R.D. Hatfield, F Lu, R.M. Ede, J. Peng, S. Quideau, R.F. Helm, J.H. Grabber, H. Kim, G. Jimenez-Monteon, Y. Zhang, H.-J.G. Jung, L.L. Landucci, J.J. MacKay, R.R. Sederoff, C. Chapple, and A.M. Boudet. In Advances in lignocellulosics Characterization. Edited by D.S. Argyropoulos. Tappi Press, Atlanta. 1999. pp. 55-108. 
Copyright $\odot 2003$ EBSCO Publishing 